\title{
A ERA DO "MULTISSINÓPTICO": QUE (NOVOS) LETRAMENTOS ESTÃO EM JOGO?
}

Petrilson Alan Pinheiro*

RESUMO: O objetivo deste artigo é, primeiramente, promover uma discussão epistemológica sobre o momento sócio-histórico atual que aqui será chamado de "multissinóptico", em que não apenas poucos observam muitos (panóptico), muitos observam poucos (sinóptico), mas, também, paralelamente, muitos observam muitos por meio de uma multi-interação constante entre pessoas no mundo inteiro na internet. Com isso, pretende-se refletir acerca do(s) modo(s) como a era atual do "multissinóptico", por meio de mudanças trazidas pela internet e, particularmente, pela web 2.0, não apenas traz transformações cruciais para as questões do "saber" e do "poder" no/por meio do ciberespaço, como também possibilita, particularmente, um repensar sobre questões relacionadas às práticas de letramento escolar, ao buscar promover relações com os conceitos de "multiletramentos" e "letramentos críticos" e suas implicações para a escola na contemporaneidade.

Palavras-chave: Multissinóptico; Multiletramentos; Letramentos Críticos; Internet; Escola.

\footnotetext{
* Doutor em Linguística pela Universidade Estadual de Campinas (UNICAMP); Professor do Departamento de Linguística Aplicada do Instituto de Estudos da Linguagem e do Programa de Pós-Graduação em Linguística Aplicada da Universidade Estadual de Campinas (UNICAMP).

E-mail: petrilsonpinheiro@yahoo.com.br
} 


\section{THE AGE OF MULTI-SINOPTYCONS:}

\section{WHAT NEW LITERACIES HAVE BECOME PART OF THE GAME?}

ABSTRACT: The objective of this paper is, first of all, to promote an epistemological discussion about the current socio-historical moment that it is named herein as "multi-synopticon". At this particular moment, not only few watch many (panopticon), many watch few (synopticon), but also, at the same time, many watch many by means of a continuous multiinteraction among people all over the world, through the Internet. Such discussion is a reflection on the ways in which the current era of the "multi-synopticon" - by means of changes brought by internet and, particularly, by the Web 2.0 - does not only bring crucial transformations for knowledge and power issues on/by means of the cyberspace, but also enables, particularly, to rethink issues related to school literacy practices, when searching to promote a relationship with the concepts of "multiliteracies" and "critical literacies" and their implications for school in contemporaneity.

Keywords: Multi-synopticon, multiliteracies, critical literacies, Internet, school.

\section{INTRODUĈ̣̃O}

A ideia da discussão teórico-epistemológica proposta neste trabalho surgiu de dois assuntos que foram amplamente divulgados na mídia internacional recentemente: o primeiro relaciona-se ao site Wikileaks, que, por meio da ação de colaboradores de diversas partes do planeta, desafia superpotências mundiais, sobretudo os Estados Unidos, com suas publicações sobre dados sigilosos governamentais na internet. Tamanha foi a repercussão do site, aliada a uma força ideológica de luta contra poderes hegemônicos globais, que seu principal criador e representante, Julian Assange, chegou a ser cotado por vários órgãos e autoridades governamentais para o Prêmio Nobel da Paz. ${ }^{1} \mathrm{O}$ outro assunto que inspirou este artigo, diretamente relacionado ao primeiro, diz respeito às manifestações contra diversos ditadores de países árabes do Norte da África e do Oriente Médio, convocadas por meio de redes sociais da internet - a famigerada "Primavera Árabe" que culminaram na saída de vários deles da presidência, como: Zine El Abidine Ben Ali, da Tunísia, Hosni Mubarak, do Egito, e Muamar Kadafi, da Líbia.

Mais recentemente, presenciamos aqui no Brasil intensas manifestações populares, também incitadas por meio de redes sociais na internet, que levaram para as ruas de diversas cidades brasileiras mais de um milhão de pessoas, cujas reinvindicações constavam desde a redução 
das tarifas no transporte público a assuntos mais gerais, como o fim da corrupção e melhorias na educação e na saúde.

Em termos epistemológicos, pode-se dizer que esses dois assuntos bem exemplificam a discussão que se pretende fazer neste trabalho: a de que estamos vivendo na era do que aqui está sendo chamado de "multissinóptico", em que não apenas poucos observam muitos (panóptico), muitos observam poucos (sinóptico), mas, também, paralela e simultaneamente, muitos observam muitos por meio de uma multi-interação constante entre pessoas no mundo inteiro pela internet.

Tomando, portanto, como base, esses conceitos, o foco deste artigo é refletir acerca do(s) modo(s) como a era atual do "multissinóptico" não apenas traz mudanças cruciais para a questão do "saber" e do "poder" no/por meio do ciberespaço, como também encaminha, particularmente, um repensar sobre questões relacionadas às práticas de letramento escolar. Para tanto, retoma-se, primeiramente, a discussão que tem sido feita entre o panóptico e o sinóptico. Em seguida, na tentativa de ir além dessa discussão, procurase mostrar o que mudou com o surgimento da internet e, particularmente, da web 2.0, e suas implicações para a questão do saber e do poder no mundo atual, propondo-se, então, o uso do termo "multissinóptico". Por fim, ao trazer a discussão para o campo dos letramentos, lida-se com as noções de "multiletramentos" e "letramentos críticos" e suas implicações na ordem do saber e do poder.

\section{O PANÓPTICO E O SINÓPTICO}

No livro Vigiar e punir, Michel Foucault discorre, no capítulo destinado à questão da disciplina, sobre a docilidade dos corpos, através da figura do soldado no século XVIII:

\footnotetext{
Segunda metade do século XVIII: o soldado tornou-se algo que se fabrica; de uma massa informe, de um corpo inapto, fez-se a máquina de que se precisa; corrigiramse aos poucos as posturas; lentamente uma coação calculada percorre cada parte do corpo, se assenhoreia dele, dobra o conjunto, torna-o perpetuamente disponível, e se prolonga, em silêncio, no automatismo dos hábitos; em resumo, foi "expulso o camponês" e lhe foi dada a "fisionomia de soldado" (FOUCAULT, 1987, p.115).
}

Essa citação, retirada da "Ordenação Militar de 20 de marco de 1764", é emblemática para representar "a descoberta do corpo como objeto e alvo de poder [...]; do corpo que se manipula, se modela, se treina, que obedece, responde, se torna hábil” (FOUCAULT, 1987, p.116). 
Essa descoberta do corpo, no século XVIII, por sua vez, passou a desencadear um "controle minucioso das operações do corpo, que realizam a sujeição constante de suas forças e lhes impõem uma relação de docilidade-utilidade, são o que podemos chamar as "disciplinas" (FOUCAULT, 1987, p.117).

Para, então, impor o exercício das disciplinas aos corpos, supõe-se um "dispositivo que obrigue pelo jogo do olhar; um aparelho em que as técnicas que permitem ver induzam a efeitos de poder, e em que, em troca, os meios de coerção tornem claramente visíveis aqueles sobre quem se aplicam" (FOUCAULT, 1987, p.143). É nesse contexto que surge, no século XVIII, um projeto de vigilância o panóptico ("Panopticon"), idealizado por Jeremy Bentham, que se constitui como uma estratégia que lança mão da arquitetura como tecnologia de poder disciplinar, que formava, segundo Foucault, a base dos planos mais efetivos de reorganização do espaço legado à observação e ao encarceramento. Trata-se, assim, de uma arquitetura que:

Não é mais feita simplesmente para ser vista (fausto dos palácios), ou para vigiar o espaço exterior (geometria das fortalezas), mas para permitir um controle interior, articulado e detalhado - para tornar visíveis os que nela se encontram; mais geralmente, a de uma arquitetura que seria um operador para a transformação dos indivíduos: agir sobre aquele que abriga, dar domínio sobre seu comportamento, reconduzir até eles os efeitos do poder, oferecê-los a um conhecimento, modificálos. O velho esquema simples do encarceramento e do fechamento - do muro espesso e da porta sólida que impedem de entrar ou de sair - começa a ser substituído pelo cálculo das aberturas, dos cheios e dos vazios, das passagens e das transparências (FOUCAULT, 1987, p.144).

É com base nessa figura arquitetural que se constitui o panóptico, que, segundo a descrição de Foucault:

É uma construção em anel na periferia; no centro, há uma torre; esta é vazada de largas janelas que se abrem sobre a face interna do anel; a construção periférica é dividida em celas, cada uma atravessando toda a espessura da construção; elas têm duas janelas, uma para o interior, correspondendo às janelas da torre; outra, que dá para o exterior, permite que a luz atravesse a cela de lado a lado. Basta então colocar um vigia na torre central, e em cada cela trancar um louco, um doente, um condenado, um operário ou um escolar. Pelo efeito da contraluz, pode-se perceber da torre, recortando-se exatamente sobre a claridade, as pequenas silhuetas cativas nas celas da periferia. Tantas jaulas, tantos pequenos teatros, em que cada ator está sozinho, perfeitamente individualizado e constantemente visível. O dispositivo panóptico organiza unidades espaciais que permitem ver sem parar e reconhecer imediatamente. Em suma, o princípio da masmorra é invertido; ou antes, de suas três funções — trancar, privar de luz e esconder — só se conserva a primeira e suprimem-se as outras duas. A plena 
luz e o olhar de um vigia captam melhor que a sombra, que finalmente protegia. A visibilidade é uma armadilha (FOUCAULT, 1987, p.165).

Essa vigilância onisciente do panóptico incute no vigiado um estado consciente e "permanente de visibilidade que assegura o funcionamento automático do poder. Fazer com que a vigilância seja permanente em seus efeitos, mesmo se é descontínua em sua ação" (FOUCAULT, 1987, p.166). O panóptico se constituiria, assim, como uma estrutura de poder extensiva a todos os âmbitos que dependessem da doutrinação das condutas, como as escolas, as fábricas, os hospitais e as prisões.

Dessarte, pode-se afirmar que, mais do que um projeto arquitetural, o panóptico é um modo de conceber e obter o poder disciplinar que constitui, segundo Foucault, dispositivos que nos atravessam; assimilamos seus mecanismos, eles se nos introjetam; aninham-se, conformam-se aos psiquismos, como, por exemplo, na sensação neurótica de estar sendo vigiado constantemente - seja em qualquer ambiente ou a sós, o panóptico está sempre presente, instalado na subjetividade.

Contudo, a imagem do panóptico, de acordo com Mathiesen, já não é eficaz para traduzir, na contemporaneidade, os dispositivos de vigilância. Em seu artigo de 1997, “The viewer society: Michel Foucault's 'panopticon' revisited", Mathiesen cria, então, o termo "sinóptico", cujo princípio, ao contrário do panóptico, em que "poucos vigiam muitos", passa a ser o de "muitos vigiam poucos".

Ao encamparo conceito de Mathiesen, Bauman (1999) assevera que o sinóptico é, ao contrário do panóptico, global por excelência, uma vez que a vigilância no sinóptico requer que os vigilantes se desprendam de suas localidades, sem que necessariamente precisem deixar seu lugar de vigilância. Nas palavras do autor:

\footnotetext{
O panóptico, mesmo quando sua aplicação era universal e quando as instituições que seguiam os seus princípios abrangiam o grosso da população, era, por sua natureza, um estabelecimento local: tanto a condição como os efeitos da instituição panóptica consistiam na imobilização dos seus súditos — a vigilância estava lá para barrar a fuga ou pelo menos para impedir movimentos autônomos, contingentes e erráticos. O sinóptico é, por sua natureza, global (BAUMAN, 1999, p.60).
}

Bauman aponta a mídia de massa como o espaço principal de constituição do sinóptico, em que muitos (as pessoas em geral) assistem — vigiam — a poucos (líderes e celebridades) — os vigiados - que, por sua vez, são estritamente selecionados. A esse respeito, Mathiesen aponta que: 
[...] sabemos quem tem permissão de penetrar de fora o meio de comunicação para expressar suas opiniões. Alguns estudos internacionais e noruegueses mostraram que, sistematicamente, são pessoas que pertencem às elites internacionais. Os que têm permissão de entrar são, sistematicamente, homens — não mulheres — das camadas sociais mais elevadas, com poder na vida política, na indústria privada e na burocracia estatal (MATHIESEN, 1997, p.61).

A perspectiva que se atribui, portanto, ao sinóptico é a de que as "os locais observam os globais e que a autoridade destes últimos é garantida por seu próprio distanciamento" (BAUMAN, 1999, p.61). A esse respeito, o autor aponta que:

Não importa mais se os alvos do sinóptico, que agora deixaram de ser os vigiados e passaram a ser os vigilantes, se movam ou fiquem parados. Onde quer que estejam e onde quer que vão, eles podem ligar-se — e se ligam — na rede extraterritorial que faz muitos vigiarem poucos. O panóptico forçava as pessoas à posição em que podiam ser vigiadas. O sinóptico não precisa de coerção — ele seduz as pessoas à vigilância (BAUMAN, 1999, p.60).

Contudo, mesmo reconhecendo a existência da diferença entre os "locais" e os "globais" e que, no sinóptico, a vigilância não ocorre mais por meio de coerção, é preciso ponderar com cautela acerca dessa diferença, que, na simplificação dicotômica apresentada por Mathiesen e Bauman, não consegue contemplar as nuances e complexidades do fluxo informacional multidirecional, multifacetado, multissemiotizado na atualidade, conforme se discute na seção seguinte.

\section{PARA ALÉM DO SINÓPTICO: O MULTISSINÓPTICO E A INTERNET}

Com efeito, a relação que Mathiesen e Bauman estabelecem entre o sinóptico e a mídia de massa parece bastante coerente, visto que os meios de comunicação em massa, sobretudo a televisão, representam fidedignamente o mote "muitos vigiam poucos". O que, no entanto, os autores desconsideram — ou não dão a devida atenção - é justamente a importância de um desses meios de comunicação que vem ganhando um espaço cada vez maior na vida social como um todo na contemporaneidade: a internet. ${ }^{2}$

A internet vem intensificando as relações sociais em escala mundial, ligando localidades antes distantes, o que tem nos proporcionado um novo tipo de vida nunca antes experimentado. As consequências dessa transformação têm grande alcance e atingem 
muitos aspectos e instâncias de nossas vidas, desde os mais íntimos aspectos da experiência em um nível micro a instâncias macro de domínio público (THOMPSON, 2004).

Nesse sentido, o local e o global tomaram uma dimensão inseparável, comparada a uma avenida infinita: numa mão, o local se torna transnacional em frações de segundo, devido à velocidade do tráfego de informação; na outra mão, o global tem chegado às mais longínquas localidades do planeta. Isso quer dizer que, em meio a esse mundo globalizado e contingente, percebe-se que as ações globais são cada vez mais afetadas pelas ações locais e vice-versa, ou, segundo Kumaravadivelu, "o global está localizado e o local está globalizado" (KUMARAVADIVELU, 2006, p.134). Isso posto, pode-se atribuir à transformação das bases materiais da vida - a fluidez do tempo e do espaço, devido a gama de informações que circulam no mundo globalizado em tempo real, a possibilidade, segundo Thompson (2004), de compartilhar de "uma visibilidade mediada", que é a transformação da própria ideia de experiência, uma capacidade reflexiva de processar novos conteúdos e de atuar em questões diversas e, como corolário, transformar a própria vida social.

Para Lévy (1999), a internet se constitui como uma grande rede interconectada mundialmente; um processo de comunicação "universal" sem "totalidade". Isso segue uma linha de comunicação que vem possibilitando aos navegantes da grande "rede" participar democraticamente de um modelo interativo feito para todos, consolidando, assim, a ideia de uma "aldeia global".

Contudo, essa participação, de fato, interativa só passou a se efetivar com o advento da web 2.0. O termo "web 2.0", utilizado para designar a segunda fase da rede mundial de computadores, foi usado por O'Reilly em um artigo de 2005, no qual ele aponta uma série de ferramentas e motivos da internet para entender uma grande mudança propriciada pela web 2.0: dos sítios (sites) estáticos da rede, que apenas serviam informação, passou-se para o desenvolvimento de comunidades dinâmicas, inseridas em uma interação entre editor e audiência.

Para entender melhor o que representa hoje a web 2.0, é preciso se reportar à geração anterior da web (web 1.0), fase em que usuários navegavam na internet com o intuito único e exclusivo de procurar informação. Era basicamente uma experiência unilateral, semelhante à ida a uma biblioteca para procurar um livro. $\mathrm{Na}$ web 1.0, os usuários da internet não eram, portanto, vistos como controladores de seus 
próprios dados. Aquilo que se obtinha na rede — a informação era, em geral, fruto do trabalho de profissionais da área que tinham os conhecimentos necessários para criar páginas da web através de programação para publicar na rede. Dessarte, a lógica da primeira geração da web era do "uso" e não da "participação"; da "recepção" e do "consumo" e não da "interatividade" e da "agência".

Diferentemente do que ocorria na web 1.0, com a consolidação e o acelerado crescimento da internet nos últimos anos, a partir do advento da web 2.0, novos mecanismos foram sendo criados, possibilitando novas condições técnicas e socioculturais para a ampliação das práticas comunicativas no mundo digital. Nesse novo ambiente, o usuário pode controlar os próprios dados. $\mathrm{Na}$ web 2.0, há, portanto, uma arquitetura de participação que inclui funcionalidades que possibilitam às pessoas não apenas receber, mas também publicar informações no sistema. Assim, mesmo que o usuário não tenha qualquer conhecimento em HTML, pode criar seus espaços na rede. A exemplo disso, é possível citar os blogs, o My Space, o Facebook, o Youtube, o Podcast, entre outros suportes digitais que possuem tecnologias que, além de possibilitarem que as pessoas estejam visíveis na web, também se tornam ambientes em que se formam redes sociais.

Com a web 2.0, houve, ipso facto, uma reconfiguração no campo da comunicação, tensionando o modelo vigente do broadcast (sistema de transmissão de informação em larga escala), em que apenas um seria responsável pela comunicação. Nessa segunda fase da web, os usuários da internet não apenas pesquisam para encontrar informação; eles também criam e publicam conteúdos, gerando, por conseguinte, uma mudança no modelo de comunicação, que passou do formato "muitos vigiam - e produzem para — poucos", para o formato "muitos vigiam e produzem para muitos". Nesse sentido, Casttells parece bastante lúcido ao apontar que as "novas tecnologias da informação não são mais simplesmente ferramentas a serem aplicadas, mas processos a serem desenvolvidos. Usuários e criadores podem tornar-se a mesma coisa" (CASTELLS, 2005, p.69).

\section{MAS O QUE ACONTECEU COM O PANÓPTICO? A COMPLEXIDADE ATUAL DOS MÚLTIPLOS OLHARES}

Atualmente, a vigilância e o controle são exercidos, conforma aponta Deleuze, através de "formas ultrarrápidas de controle ao ar 
livre, que substituem as antigas disciplinas que operavam na duração de um sistema fechado" (DELEUZE, 1992, p.221). Não há dúvidas, portanto, de que os mecanismos de controle e sujeição se sofisticaram e de que, na sociedade de controle, a vigilância independe de qualquer confinamento territorial. Atualmente, câmeras espalhadas pelo mundo inteiro, mormente câmeras móveis de celulares, de tablets e de todos os tipos de "i" (ipods, iphones, ipads) vigiam nossos passos no dia a dia e podem, a qualquer momento, descarregar o que fazemos no Youtube. Todavia, não se pode descartar o fato de que, tal como ocorria no panóptico, o controle ainda é exercido em espaços confinados institucionais, como em escolas, por exemplo, através de câmeras instaladas em diversos pontos estratégicos, cuja função ainda é a de vigiar e manter a disciplina (típica do panóptico), que pressupõe o olhar vigilante, que agora opera de forma mais sofisticada, em sua sala de computadores, ao menor sinal de transgressão às regras.

Assim, podemos dizer que, apesar de transmutado em função de novas TIC, o panóptico ainda existe em nossa sociedade. No entanto, contrariando Bauman, que apontava que a "elogiadíssima 'interatividade' do novo veículo (a internet) é um grande exagero, pois deveriam antes falar num meio interativo one-way" (BAUMAN, 1999, p.101), o início do século XXI é marcado pelo que aqui se está chamando de "multissinóptico". Este se constitui por meio do crescimento cada vez maior de novos produtores de conteúdo, que, com a web 2.0, geram referências, na maioria das vezes, resultantes de experiências que as pessoas têm com outras referências, em um nível cada vez mais pessoal, e, portanto, não apenas com grandes sites ou instituições, tal como se costumava fazer antes (no panóptico e no sinóptico). Com efeito, isso passa também a possibilitar que uma ideia, tão logo seja concebida, já se torne pública, entre em "competição cooperativa no ciberespaço com as outras e, eventualmente, comece a ganhar forma num documento, num software, num produto, numa empresa, numa organização, numa comunidade virtual ou numa rede" (LÉVY, 2003, p.24).

Assim, a atual "era do multissinóptico" traz em seu bojo novas (re)configurações que possibilitam, do ponto de vista individual, algo que, embora seja muito anterior ao surgimento das novas TICs, se potencializou e tomou proporções nunca experimentadas na história com o advento da internet. Nesse sentido, nota-se que, cada vez mais, blogs e redes sociais se tornaram espaços de autopromoção, em que milhões de pessoas no mundo inteiro exibem seus "perfis" para os outros na tentativa de se tornar celebridades. A web 2.0 democratizou a "fama" 
na internet com a cultura do "broadcast yourself", através de milhares de vídeos que são diariamente postados no Youtube por pessoas que desejam se tornar celebridades. Nesse sentido, pode-se dizer que, se o sinóptico "é, por natureza, global" (BAUMAN, 1999, p. 60), o multissinóptico é global e local, pois, ao mesmo tempo em que o ato de vigiar desprende os indivíduos de sua localidade para vigiar os outros (globalmente), também converge a vigilância (intencionalmente ou não) para si mesmos, em um fluxo contrário que parte do olhar global para as suas ações locais.

Do ponto de vista coletivo, percebe-se o quanto o novo modelo de broadcast possibilita aos usuários da internet, ao se verem mais livres de amarras institucionais e editoriais, divulgar informações de interesse público na rede, que, muitas vezes, saem na frente dos meios de comunicação tradicionais. Por exemplo, em março de 2011, um forte terremoto de grande magnitude atingiu a costa do Japão, causando a morte de muitas pessoas. Pouco depois do terremoto, os 20 vídeos noticiosos mais assistidos no Youtube eram relacionados ao fato. Eles foram vistos mais de 96 milhões de vezes. O interessante é que a maior parte dos vídeos não foi postada pelos veículos de mídia tradicionais, mas por cidadãos comuns. $\mathrm{O}$ que as pessoas viram nesses vídeos representou, de fato, um novo tipo de jornalismo.

Com efeito, esse exemplo mostra o quanto a internet vem se tornando um espaço democrático, marcado pela possibilidade de atuação direta dos usuários na rede e, por conseguinte, na esfera pública. A esse respeito, Lévy (2003, p. 56) afirma que:

A principal vantagem da internet, relativamente aos meios de comunicação da democracia mediática da segunda metade do século XX (imprensa, rádio e televisão), é que permite a todos os agentes se exprimir sem ter de passar pelo poder do jornalista. Resultado: a esfera pública alarga-se, diversifica-se e complicase particularmente. Essa mutação da esfera pública constitui um dos fundamentos da ciberdemocracia (LÉVY, 2003, p.56).

Com efeito, com o advento e o uso cada vez mais intenso de novas TICs, as possibilidades de ação política e o papel dos Estados têm sido objetos de reflexão. Não parece haver dúvida de que a internet, de uma certa forma, limitou o poder dos Estados, ao possibilitar a eclosão de novos movimentos sociais, por meio de ações locais com interesses específicos e potencial universalizável. Pode-se dizer, por exemplo, que indícios dessa ciberdemocracia tenham sido notados, conforme apontado na introdução deste artigo, na famigerada "Primavera Árabe", insurgida por meio de fortes manifestações populares contra 
diversos ditadores de países árabes do Norte da África e do Oriente Médio, em 2011, convocadas por meio de redes sociais da internet (Twitter, Facebook, Youtube e blogs), que culminaram na queda de vários ditadores, como: Zine El Abidine Ben Ali, da Tunísia, Hosni Mubarak, do Egito, e Muamar Kadafi, da Líbia.

Contudo, mesmo reconhecendo que o modelo de broadcast vem se transformando com o advento de novas TICs, em particular, com a web 2.0, e que isso tem trazido implicações importantes em termos de produção, divulgação e consumo da informação, é preciso ter cautela com determinadas afirmações sobre o complexo cenário atual. Dizer, por exemplo, que as instituições têm menos poder nas decisões tomadas por usuários na rede, uma vez que estes encontram mecanismos para escapar de seus tentáculos, parece sensato, tanto em nível local quanto global. Todavia, afirmar, com isso, que as pessoas estão livres de qualquer tipo de sanção institucional na internet não é um truísmo, pois a construção da vida pública no ciberespaço também está criando muitos novos intermediários, muitos dos quais invisíveis.

Esses novos intermediários vêm sendo usados na internet, de uma forma ou de outra, como mecanismos de controle. Por exemplo, os consumidores, no ciberespaço, de qualquer parte do planeta, estão menos anônimos do que pensam, pois sites da internet, como Google, Facebook e ComScore - para não mencionar outros compartilham informações e nomes de usuários com outros sites. Por meio de cookies e bots, ${ }^{3}$ é possível capturar dados de usuários, conforme estes navegam na internet, identificando suas ações na rede para companhias de marketing, que coletam um perfil completo de seus comportamentos on-line.

Em países com regimes não democráticos, tais intermediários são ainda usados como uma espécie de mecanismo de censura, suprimindo opiniões dissidentes por meio da ajuda de empresas nacionais de tecnologia. $\mathrm{Na}$ China, por exemplo, mais de 200 contas em redes sociais foram encerradas em 2012 por divulgarem conteúdo "vulgar", segundo o Gabinete de Informação Estatal da Internet do governo chinês. Mais da metade das contas estavam no site de microblogs Weibo, a versão chinesa do Twitter. Por essa razão, muitos usuários de blogs na China começaram, então, a tentar burlar a censura, utilizando alusões e eufemismos em seus textos para contornar os algoritmos de censura, como o uso da expressão "terapia de férias", empregada para descrever a detenção de funcionários do governo. 
Na Rússia, do mesmo modo, o governo, no final de 2011, invadiu redes sociais na tentativa de conter a maior onda de protestos desde o fim da União Soviética contra as supostas fraudes ocorridas no processo eleitoral à presidência. Após a divulgação de um vídeo no Youtube, que mostra um funcionário do governo preenchendo a ficha de votação para uma senhora idosa (contabilizando mais um voto para o partido pro-Putin), milhares de pessoas começaram a protestar via Twitter. O governo russo, por sua vez, também infestou o Twitter de bots, com mais de 10 mensagens por segundo, com mensagens pró-governo, confundindo, assim, o debate pela rede social. O governo ainda tentou convencer a maior rede social do país, VKontakte, a deletar as mensagens que incentivavam os protestos contra as eleições.

Os tais "intermediários" ainda atuaram contra o site Weakleaks, que, justamente por desafiar superpotências mundiais, sobretudo os Estados Unidos, com suas publicações sobre dados sigilosos governamentais na internet, teve suas atividades supensas por falta de recursos financeiros. Isso porque o sistema Paypal, que permite a transferência de dinheiro entre indivíduos ou empresas via internet, suspendeu o serviço de pagamento das doações que sustentavam o site.

À luz da discussão feita até aqui acerca das potencialidades de uso da internet, tanto para revolucionar quanto para controlar, na era do que se está chamando de "multissinóptico", nota-se, portanto, que a questão é mais complexa do que se observava no panóptico e no sinóptico. Por exemplo, quando se discute acerca do "banco de dados", Bauman aponta que, no panóptico, "esperava-se e exigia-se uma conduta monótona e rotineira; o banco de dados registra os consumidores confiáveis e dignos de crédito" (BAUMAN, 1999, p.58). No sinóptico, "ser incluído no banco de dados é a condição primordial da 'credibilidade', e este é o meio de acesso à 'melhor oportunidade local'." Em outras palavras, embora o banco de dados seja, conforme aponta o próprio autor, um instrumento de seleção, separação e exclusão, pertencer ao banco de dados, na lógica do sinóptico, é condição a priori de credibilidade e de aceitação. No entanto, ao pensar a partir da perspectiva do multissinóptico, o banco de dados assume também um outro caráter, pois, quando o Facebook se utiliza da estratégia de vender para empresas de marketing o acesso aos seus usuários, passando a tornar públicas categorias inteiras de informações, como as compras on-line dos usuários, com fins mercadológicos, pertencer ao "banco de dados" já não é desejável, muito menos digno de credibilidade ou de aceitação. 
Assim, o multissinóptico, para além do panóptico e do sinóptico, se constitui de uma forma bem mais complexa diante do fluxo informacional e comunicacional multidirecional, multifacetado, multissemiotizado no mundo atual. Mas, quando nos deparamos com a escola, como esse olhar "multissinóptico" pode nos ajudar a compreender as experiências de letramento escolar e a repensá-las à luz desse mundo atual?

\section{NA ERA DOS “MULTI”, O QUE É SER MULTILETRADO?}

O exercício do poder de vigilância e controle ainda prevalece em espaços confinados institucionais, tal como ocorria no panóptico. No entanto, diferentemente de outras épocas, hoje, por serem onipresentes e quase desprovidas de materialidade, as novas TICs não necessitam de construções específicas, pois os equipamentos eletrônicos se adaptam perfeitamente ao interior de todos os espaços já existentes, o que torna o poder da vigilância ainda mais eficiente. Nas escolas, em particular, câmeras instaladas em diversos pontos estratégicos, bem como o uso de cartões digitais, são exemplos típicos de mecanismos eficientes de vigilância e controle dos alunos, sempre prontos a acusar o menor sinal de transgressão às regras.

Mesmo em escolas menos tecnologizadas, a vigilância e o controle dos alunos não são menos intensos. Se observarmos a própria organização da grande maioria das salas de aula das escolas, cujo modelo se mantém inalterado nos últimos dois séculos, nota-se, por exemplo, que a própria disposição física das carteiras escolares em fileiras (um aluno atrás do outro), que impedem que os alunos possam ver um ao outro, com o professor ocupando uma posição central (mais alta) à frente dos alunos, nada mais é que um modo de organização típico do panóptico, de que se vale o professor para vigiar e controlar seus alunos (movimentos, conversas paralelas entre si, turno de fala de cada aluno).

Podemos ir mais longe ao dizer que, assim como a organização escolar, as práticas de letramento adotadas nas escolas em geral se encontram, do mesmo modo, distantes de promover um olhar mais amplo para as práticas sociais multifacetadas e multissemiotizadas do mundo atual (multissinóptico).

$\mathrm{Na}$ tentativa, então, de procurar entender que o letramento escolar (grafocêntrico), embora ainda importante, não é suficiente para dar conta, na contemporaneidade, das mudanças constantes, 
tanto local quanto globalmente, em função da presença cada vez maior de novas TICs, é que um grupo de pesquisadores de diversos países, conhecidos por The New London Group (NLG), publica, em 1996, o artigo "A pedagogy of multiliteracies: designing social futures", cujo interesse comum é discutir uma pedagogia direcionada para os multiletramentos.

As propostas de trabalho do grupo estão voltadas para os estudos semióticos dos textos, envolvendo as diferentes formas de produzir, veicular e consumir textos, expandindo, assim, o conhecimento sobre letramento. Isso é feito na conexão entre dados empíricos e teoria social, que incluem as relações de poder, de identidade cultural e do conhecimento científico. Tais estudos passam, assim, a ter seu escopo ampliado em decorrência do surgimento das novas TICs. Assim, surge uma nova pedagogia para que os indivíduos possam aprender a dominar e a interagir com esses avanços tecnológicos, a pedagogia de multiletramentos (COPE; KALANTZIS, 2000).

Ainda segundo o grupo, o termo multiletramentos se apoia em dois principais argumentos:

[...] o primeiro está relacionado à crescente multiplicidade e integração de modos de construção de significado, em que o textual está integrado ao visual, ao áudio, ao espacial e ao comportamental, etc. Isso é particularmente importante na mídia de massa, na multimídia e na hipermídia eletrônica (NLG, 1996, p.64).

Assim, os significados, hoje, passam a ser construídos de maneira multimodal, podendo vir da internet, dos vídeos, da multimídia ou dos textos escritos do cotidiano, como de lojas e de placas, pois, como apontam Cope e Kalantzis, "em um profundo sentido, toda construção de significado é multimodal" (COPE; KALANTZIS, 2000, p.29).

O segundo argumento se apoia nas diferenças culturais e linguísticas da nossa sociedade cada vez mais globalizada. Segundo os pesquisadores do grupo,

[...] lidar com as diferenças linguísticas e culturais tornou-se central para a pragmática de nossas vidas profissionais, cívicas e privadas. Uma efetiva cidadania e um trabalho produtivo requerem que possamos interagir efetivamente usando múltiplas linguagens, em múltiplos ingleses e padrões de comunicação que cruzam fronteiras nacionais, culturais e comunitárias (NLG, 1996, p.64).

Para o grupo de pesquisadores, a pedagogia dos multiletramentos é fundamental, visto que os sujeitos que frequentam os ambientes 
escolares de hoje são outros; suas vivências, que, em geral, são cada vez mais globais, lhes possibilitam lidar com uma imensa diversidade linguística e cultural. Assim, os pesquisadores do NLG defendem um ensino voltado para projetos que considerem as diferenças multiculturais existentes no alunado contemporâneo, dando visibilidade à dimensão profissional, à dimensão pessoal e à dimensão da participação cívica.

É nesse sentido que precisamos considerar, segundo Rojo (2009), uma educação linguística que veja o aluno como um sujeito inserido em práticas sociais, dentro e fora do ambiente escolar, e que, portanto, lhe possibilite participar de diferentes práticas de letramentos, ou melhor, de multiletramentos, visto que as práticas de letramento tradicionais parecem não ser mais suficientes para dar conta de preparar o aluno para a produção e recepção de textos que se apresentam cada vez mais multifacetados na contemporaneidade. A esse respeito, Moita Lopes e Rojo afirmam que:

A compreensão de que vivemos em um mundo multissemiótico (para além da letra, ou seja, um mundo de cores, sons, imagens e design que constroem significados em textos orais/escritos e hipertextos) e de que é necessário entender tal mundo, para que seja possível fazer escolhas entre os discursos que se apresentam, tem transformado a educação linguística em peça fundamental para enfrentar os desafios da contemporaneidade na construção da cidadania (MOITA LOPES; ROJO, 2004, p.39).

Com efeito, é preciso ter um olhar atento para as novas TICs, pois a velocidade dos meios de comunicação e de produção, a volatilidade do capital e o acesso aos estoques mundiais de informação, possibilitados pela inserção das TICs, vêm exercendo, conforme apontam Cope e Kalantzis (2000), grandes mudanças nas mais variadas instâncias da vida social. Dentre essas TICs, um destaque especial deve ser dado à internet, que tem se tornado um elemento cada vez mais marcante na vida cotidiana de milhões e milhões de pessoas, mormente dos adolescentes. Isso porque muitos desses adolescentes já estão imersos na "era digital" e, por isso, não conseguem simplesmente conceber o mundo sem a existência da internet; preferem

[...] a informação imediata, gráficos, animações, áudio e vídeo ao texto simples, e interagem naturalmente com outros enquanto realizam multitarefas. Para eles, fazer é mais importante do que saber, e aprender tem que ser algo divertido e imediatamente relevante (FIELDHOUSE; NICHOLAS, 2008, p.60 - itálico no original). 
Tomando como base essa experiência cada vez intensa dos mais jovens com o mundo digital, Snyder argumenta que, muito embora o uso de novas TICs na escola seja, por muitos críticos, "associado à trivialidade da cultura popular", o fato de as "mídias eletrônicas dominarem as vidas dos alunos como parte de um mundo cada vez mais conectado" já seria, para a autora, mais do que suficiente para incluí-las no currículo escolar (SNYDER, 2008, p.158).

Embora a autora esteja se referindo especificamente às escolas australianas, é possível estender essa visão para o contexto das instituições escolares públicas brasileiras, pois a internet tem sido acessada por um número cada vez maior de usuários no Brasil, sobretudo por adolescentes, que, em geral, são os que mais dominam — e se sentem atraídos por — essa tecnologia. Isso, por si só, já seria um motivo bastante razoável para a inclusão da internet nas escolas brasileiras, que, em geral, ainda se encontram na era "pré-virtual". ${ }^{4}$

Contudo, a instalação de laboratórios de informática equipados com internet em escolas públicas não basta para tornar os alunos letrados na sociedade atual cada vez mais hiperssemiotizada, pois, além de investimento material, é preciso haver, sobretudo, investimento humano. Isso quer dizer que, se, por um lado, tem havido um certo empenho governamental para levar tecnologia às escolas públicas brasileiras, por outro, o próprio governo parece negligenciar uma outra questão de suma importância: a falta de um melhor preparo dos próprios profissionais da educação, mormente dos professores, ${ }^{5}$ que, em geral, ainda não sabem como fazer para que essa tecnologia que chega às escolas possa se tornar, de fato, produtiva para o processo de ensino-aprendizagem. Como exemplo disso, é possível mencionar o Programa Nacional de Tecnologia Educacional do Ministério da Educação (ProInfo), que, embora seja tratado como um programa educacional com o objetivo de promover o uso pedagógico da informática na rede pública de educação, ainda se restringe a levar às escolas públicas brasileiras recursos digitais (computadores, acesso à internet e materiais digitais de apoio), porquanto transfere aos estados e municípios a responsabilidade de garantir a estrutura adequada para receber os laboratórios e capacitar os educadores para uso dos recursos tecnológicos.

Em consequência dessa visão, encontram-se, hoje, por um lado, milhares de escolas equipadas com laboratórios de informática, com computadores ligados à internet banda larga, e, por outro, muitos professores que sequer conseguem ver a internet como algo 
que possa ser, de fato, integrado às suas aulas. Isso, é claro, está relacionado à formação e capacitação docente, mas passa também por outras questões, como o receio, e até o preconceito, de lidar com o novo - no caso, a internet. Há, por outro lado, muitos professores que já usam, de alguma forma, a internet como parte de suas aulas. No entanto, a maioria desses professores ainda se restringe à utilização da internet com o fim exclusivo de buscar informações na rede (no Google, por exemplo), ou usar um editor de texto (como o Word), apesar da infinidade de opções que o ambiente da hipermídia oferece aos seus usuários - e que os alunos, em geral, conhecem bem melhor do que os próprios professores.

Assim, para que se possa contemplar um ensino a partir de práticas multiletradas, é preciso considerar, portanto, que a pura e simples inserção de novas TICs na escola, por si só, não é capaz de responder às necessidades e exigências de um trabalho bem-sucedido que articule o uso da internet e as práticas de escrita escolares. A esse respeito, SØby argumenta que:

As novas TICs não irão, por si só, criar inovação e novos espaços para a aprendizagem. O potencial da mídia digital só pode ser percebido se estiver ancorado em um contexto pedagógico, social e organizacional apoiado por um compromisso político (SØBY, 2008, p.129).

Esse "compromisso político" a que o autor se refere é o que, em outras palavras, faz com que o simples uso de novas técnicas em uma prática de letramento não se constitua como um novo letramento, uma vez que é possível usar novas TICs para simplesmente replicar antigas práticas de letramento, como ainda acontece bastante no contexto escolar. A esse respeito, Knobel e Lankshear apontam que:

[...] O que é central para os novos letramentos não é o fato de que podemos agora 'procurar informações on-line' ou escrever redações usando um processador de textos ao invés de uma caneta ou uma máquina de escrever, mas sim que as novas tecnologias mobilizam tipos de valores, prioridades, sensibilidades, normas e procedimentos muito diferentes dos letramentos com os quais estamos familiarizados (KNOBEL; LANKSHEAR, 2007, p.7).

Assim, para os autores, além de se experimentar o surgimento de novos aparatos digitais ("new technical stuff"), também é preciso passar por revisões conceituais ("new ethos stuff"), para que se possa, de fato, pensar um novo letramento. Tais revisões conceituais envolvem, por sua vez, uma postura crítica em relação às ações e às dominações sociais existentes e, portanto, toda prática de letramento 
tem um papel fundamental no processo de esclarecimento, de emancipação e de formação da criticidade dos discentes.

É nesse sentido que alguns autores (GEE, 1996; CERVETTT; PARDALES; DAMICO, 2001; LUKE, 2004, entre outros) propõem uma teoria do letramento crítico, fortemente influenciada pela teoria crítica social (FREIRE, 1981), cujo principal objetivo está em considerar as práticas de letramentos como práticas sociodiscursivas que possibilitam a compreensão e o questionamento de forças ideológicas e de poder com vistas à emancipação e à transformação do indivíduo.

Assim, o conceito de letramento crítico prevê que as práticas de letramento se constituem por meio de representações da realidade moldadas ideologicamente e que o aluno deve estar consciente de tais representações para aprender a se posicionar criticamente em relação a elas (CERVET'TI; PARDALES; DAMICO, 2001). Nesse sentido, ser letrado criticamente é, nas palavras de Paulo Freire, estar "não apenas 'no mundo', mas 'com o mundo" (FREIRE, 1981, p.53), ou seja, ser capaz de poder agir dentro e sobre seu contexto local e global, permitindo seu empoderamento com vistas a uma sociedade mais justa e democrática.

Ao levar tal visão do letramento crítico para as complexas relações no ciberespaço, podemos dizer que este possibilita, primeiramente, um grau de interatividade (inexistente na perspectiva do panóptico e pouco diversificada na perspectiva do sinóptico) que está diretamente relacionado à performance, dando oportunidade ao usuário de participar direta e ativamente na construção do significado. Nesse sentido, o processo de interação na rede cibernética é ativo e social, permitindo, assim, múltiplos pontos de vista.

Pode-se, portanto, dizer que a interatividade traz consigo uma desestabilização da noção de autoria, o que, por sua vez, traz uma reconfiguração da própria noção de conhecimento, pois este já não é mais produto unilateral de seres humanos isolados, mas de uma vasta cooperação cognitiva distribuída. Tais (re)configurações criam, por sua vez, um novo ethos na web 2.0; um ethos cuja base está no descentramento da noção de autoria e na celebração da "inclusão", na participação em massa do processo produtivo, na distribuição de expertise e na participação e colaboração ativas, promovendo, assim, novas práticas de leitura e escrita, ou melhor, "novos letramentos" (KNOBEL; LANKSHEAR, 2007), como o letramento digital.

Por outro lado, diante de um ambiente aberto e público para que qualquer um possa produzir seu blog, sua página ou seu perfil em sites de relacionamentos, é possível afirmar que o "ser letrado 
crítico" está, mais do nunca, relacionado ao fato de que, na era atual do multissinóptico, a internet, conforme apontado acima, pode ser útil tanto para revolucionar quanto para controlar; tanto para divulgar informações relevantes, quanto informações de caráter duvidoso (do ponto de vista conceitual, quanto ideológico). Nesse sentido, o que difere um simples usuário de um letrado crítico é o fato de o primeiro estar apenas interessado em buscar informações na rede, enquanto o segundo, por outro lado, se mostra também preocupado com a análise e avaliação das fontes de informações disponibilizadas no mundo digital, bem como com as regras e convenções que o habilitam a agir no sentido de fazer uso de tais informações, como questões autorais, por exemplo. "Ser letrado crítico" se torna, por conseguinte, um sujeito que não apenas reconhece e transita por diferentes espaços hipertextuais, mas busca compreender os diferentes mecanismos que regem a produção, reprodução e difusão da escrita na rede.

Ter um olhar crítico sobre o que circula no mundo digital, portanto, é, de uma certa forma, estar mais preparado para participar do mundo contemporâneo. No entanto, para que seja possível lidar com essas questões, espera-se que a escola passe a se envolver com as novas TICs, que não são uma opção para o ensino, mas uma realidade inevitável que se constitui em função de uma nova concepção do saber, um "saber-fluxo", que exige a construção de novos modelos de espaços de conhecimentos. Ou, nas palavras de Lévy,

O saber-fluxo, o saber-transação de conhecimento, as novas tecnologias da
inteligência individual e coletiva estão modificando profundamente os dados do
problema da educação e da formação. O que deve ser aprendido não pode mais
ser planejado, nem precisamente definido de maneira antecipada. Os percursos
e os perfis de competência são, todos eles, singulares e está cada vez menos
possível canalizar-se em programas ou currículos que sejam válidos para todo
o mundo. Devemos construir novos modelos do espaço dos conhecimentos.
A uma representação em escalas lineares e paralelas, em pirâmides estruturadas
por "níveis", organizadas pela noção de pré-requisitos e convergindo até saberes
"superiores", tornou-se necessário doravante preferir a imagem de espaços de
conhecimentos emergentes, abertos, contínuos, em fluxos, não lineares, que se
reorganizam conforme os objetivos ou contextos (LÉVY, 1999, p.158).

Esse "saber-fluxo", que se constitui com base na noção de conhecimento ad hoc, sempre dinâmico e em movimento, possibilitado, sobretudo, pelo advento da internet, está dando origem a novos modos de construir uma nova "inteligência coletiva", menos preza a disciplinas e regras. A esse respeito, Jenkins pondera que: 
O ponto ao mesmo tempo forte e fraco da inteligência coletiva é a sua desorganização, sua falta de disciplina e de regras. Assim como o conhecimento é ad hoc, não existem procedimentos fixos sobre o que fazer com esse conhecimento. Cada participante aplica suas próprias regras e trabalha com os dados através dos próprios processos, alguns dos quais serão mais convincentes que outros, mas nenhum deles é errado, à primeira vista (JENKINS, 2008, p.88).

Contudo, o fato de a internet estar contribuindo para mudanças no modo como se concebe o saber não quer dizer, ao contrário do que muitos vêm professando de forma sensacionalista, que estamos diante do "determinismo tecnológico", cujas qualidades tecnológicas seriam as grandes responsáveis pelas mudanças que inevitavelmente afetam as relações sociais. Tampouco o inverso seria um truísmo: o do "determinismo social", em que as próprias pessoas, e não a tecnologia, seriam os únicos responsáveis pelo fenômeno da transformação digital na era da informação. Contra essas posições antitéticas, é preciso entender que a relação entre ser humano e tecnologia se constitui de forma dialética, em que se reconhece que as TICs produzem, de fato, efeitos nas pessoas, mas estas, por sua vez, moldam seus usos nas práticas sociais das quais participam. Entender essa relação dialética faz parte do letramento crítico e deve ser, portanto, objeto de ação para o desenvolvimento de uma visão crítica sobre a construção de conhecimento na era do multissinóptico.

\section{CONSIDERAÇÕES FINAIS}

Ao tomar como base os conceitos de "panóptico", em que 'poucos observam muitos', e de "sinóptico", em que 'muitos observam poucos', procurou-se desenvolver, neste trabalho, a ideia de que estamos vivendo atualmente a era do que aqui se convencionou chamar de "multissinóptico", uma era mais complexa, em que não apenas 'poucos observam muitos', e 'muitos observam poucos', mas também, paralela e simultaneamente, muitos observam muitos por meio de uma multi-interação constante entre pessoas, no mundo inteiro, por meio do/no ciberespaço.

Mostrou-se também como a era atual do "multissinóptico" não apenas traz mudanças cruciais para a questão do "saber" e do "poder", como também encaminha, particularmente, um repensar sobre questões relacionadas às práticas de letramento escolar, ao buscar uma relação entre a web 2.0, os "multiletramentos" e o "letramento crítico", com o intuito de entender as implicações de 
tal relação na ordem do saber e do poder e suas possibilidades de mudanças nas práticas de leitura e escrita escolares.

Portanto, na era do "multissinóptico", é preciso, primeiramente, que as práticas de letramento escolar sejam (re) vistas com base na perspectiva dos multiletramentos, pois, em primeiro lugar, deve-se reconhecer que, hoje, mais do que nunca, toda construção de significado é multimodal; e que, em um mundo cada vez mais globalizado, é preciso saber lidar cada vez mais com as diferenças, porquanto os sujeitos que frequentam os ambientes escolares de hoje são outros; suas vivências que, em geral, são cada vez mais globais, lhes possibilitam lidar com uma imensa diversidade linguística e cultural.

Lidar com a diversidade, procurando dar visibilidade às dimensões pessoal (privada) e de participação cívica (pública), está, portanto, relacionado à perspectiva do letramento crítico, que busca questionar forças ideológicas de poder e saber, com vistas à emancipação e transformação do indivíduo. É, portanto, na perspectiva do letramento crítico que se reconhece que "não há relação de poder sem constituição correlativa de um campo de saber, nem de saber que não suponha e não constitua ao mesmo tempo relações de poder" (FOUCAULT, 1979, p.32).

Ao se buscar relacionar essa questão do "saber-poder" com a discussão desenvolvida neste artigo, é possível sim afirmar que as mídias sociais não apenas desafiam os modos tradicionais de transmissão, comunicação e participação, mas também os moldam. De fato, as mídias sociais permitem aos usuários criar conteúdo e interagir uns com os outros de modo colaborativo para diversos fins.

Por outro lado, procurou-se, outrossim, mostrar que governos e, sobretudo, corporações (grandes e não tão grandes) estão ganhando mais poder sobre nossos comportamentos e crenças. Mídias sociais corporativas como Facebook, Google e Twitter já se tornaram superpotências informacionais e comunicacionais. E, por mais estranho e até paradoxal que possa parecer, quanto mais as mídias sociais corporativas possibilitam colaboração social e participação cívica entre pessoas em geral, mais essas próprias mídias se tornam mais importantes.

Tendo em vista, portanto, a discussão até aqui feita, entendese que a internet não deve ser encarada como uma panaceia para a solução dos problemas políticos, sociais e educacionais, muito embora tenha potencial para criar e desenvolver muitas propostas interessantes. Tampouco deve ser considerada como um instrumento 
de subsídio para totalitarismos apoiados por manipulação de programas e informações, muito embora algumas nações, de vez em quando, ensaiem algumas estratégias que caminham, de alguma forma, nessa direção.

É preciso, pois, que se tenha olhar crítico e mais amplo acerca do mundo multissinóptico atual, para que se possa estar sensível aos contextos locais e suas complexas conexões geopolíticas globais. Mas, em meio a essas complexas relações entre o local e o global, já não se pode negar que as formas tradicionais de poder, exercidas através de sistemas de dominação centralizados, que agem de cima para baixo (a forma prototípica do panóptico — atente-se para a própria estrutura arquitetônica da torre projetada por Jeremy Bentham, cuja posição do observador the permitia vigiar e controlar as pessoas de cima para baixo!), estão sendo cada vez mais substituídas por outras formas de poder. Nesse sentido, o próprio deslocamento das instituições para as redes vem tornando seu poder menos hierárquico (verticalizado) e mais heterárquico (redes horizontais participativas); menos autoritário e coercitivo e mais difuso e extensivo (colaborativo e cooperativo); menos centralizado e mais periférico; menos marcado por fronteiras e mais aberto para o ciberespaço. Ações como a do Wikileaks e a da "Primavera Árabe" vêm ensaiando essas mudanças promissoras!

\section{REFERÊNCIAS}

BARTON, D.; HAMILTON, M. Local literacies: reading and writing in one community. London: Routledge, 1994.

BAUMAN, Z. Globalização: as consequências humanas. Rio de Janeiro: Zahar, 1999.

BAUMAN, Z. Modernidade líquida. Rio de Janeiro: Zahar, 2001.

CANCLINI, N. G. Diferentes, desiguais e desconectados. Trad. Luiz Sérgio Henriques. Rio de Janeiro: UFRJ, 2005.

CERTEAU, M. de. A invenção do cotidiano: artes de fazer. Petrópolis: Vozes, 1996.

CERVETTI, G.; PARDALES, M. J.; DAMICO, J. S. A tale of differences: comparing the traditions, perspectives and educational goals of critical reading and critical literacy. Reading Online, v.4, n.9, apr. 2001. Disponível em: < http://www.readingonline.org/articles/art_ index.asp?HREF=articles/cervetti/index.html>. Acesso em: 20 jun. 2011.

COPE, B.; KALANTZIS, M. (Eds.). Multiliteracies: literacy learning and the design of social futures. Londres: Routledge. 2000.

DELEUZE, G. Conversações. Rio de Janeiro: Editora 34, 1992.

FIELDHOUSE, M.; NICHOLAS, D. Digital literacy as information savvy: the road to information literacy. In: LANKSHEAR, C.; KNOBEL, M. Digital literacies. New York: Peter Lank, 2008. p.47-72.

FOUCAULT, M. Microfísica do poder. Rio de Janeiro: Graal, 1979.

FOUCAULT, M. Vigiar e punir: nascimento da prisão. Petrópolis: Vozes, 1987.

FREIRE, P. Ação cultural para a liberdade. 5.ed. Rio de Janeiro: Paz e Terra, 1981. 
FREITAS, M. T. A. Bakhtin e Vygotsky: um encontro possível. In: BRAIT, B. (Org.).

Bakhtin, dialogismo e construção do sentido. São Paulo: Editora da Unicamp, 1997. p.311-330.

GEE, J. P. Social linguistics and literacies: ideology in discourses. $2^{\text {nd }}$ ed. London: Taylor \& Francis, 1996.

GRAFF, H. The legacies of literacy. The American Educational Research Association, 1994. HEATH, S. B. Ways with words. Cambridge: Cambridge University Press, 1983.

JENKINS, H. Cultura da convergência. São Paulo: Aleph, 2008.

KALANTZIS, M.; COPE, B.; HARVEY. Assessing multiliteracies and the newbasics. Assessment in Education, 10(1), p.15-26, 2003.

KINCHELOE, J. L. A formação do professor como compromisso político: mapeando o pós-moderno. Porto Alegre: Artes Médicas, 1997.

KLEIMAN, A. Modelos de letramento e as práticas de alfabetização na escola. In: KLEIMAN, A. (Ed.). Os significados do letramento. Campinas: Mercado de Letras. 1995.

KNOBEL, M.; LANKSHEAR, C. A new literacies sampler. New York: Peter Lang Publishing, Inc., 2007.

KUMARAVADIVELU, B. A. Linguística aplicada na era da globalização. In: MOITA

LOPES, L. P. (Org.). Por uma linguística aplicada indisciplinar. São Paulo: Parábola. 2006. p.129-148.

LÉVY, P. Cibercultura. São Paulo: Editora 34, 1999.

LÉVY, P. A conexão planetária: o mercado, o ciberespaço, a consciência. São Paulo: Editora 34, 2001.

LÉVY, P. Ciberdemocracia. Lisboa: Instituto Piaget, 2003.

LUKE, A. Foreward. In: McLAUGHLIN, M.; DEVOOGD, G. Critical literacy: enhancing students' comprehension of text. New York: Scholastic, 2004. MATHIESEN, T. The viewer society: Michel Foucault's 'panopticon' revisited. Theoretical Criminology, v.1, n.2, p.215234, 1997.

MOITA LOPES, L. P.; ROJO, R. H. R. Linguagens, códigos e suas tecnologias. In: BRASIL/DPEM. Orientações curriculares do ensino médio. Brasília: MEC/SEB/ DPEM, 2004. p.14-59.

NEW LONDON GROUP. A pedagogy of multiliteracies designing social futures. Harvard Educational Review, 66(1), p.60-92, 1996.

NOFFKE, S.; BRIDGET, S. Action research. In: SOMEKH, B.; LEWIN, C. Research methods in social sciences. London: Sage, 2005. p.89-96.

O'REILLY, T. What is web 2.0?: design patterns and business models for the next generation of software. Disponível em: http://oreillynet.com/pub/a/oreilly/tim/news/2005/09/30/ what-is-web-20.html. Acesso em: 4 apr. 2011.

ROJO, R. H. R. Letramentos múltiplos, escola e inclusão social. São Paulo: Parábola, 2009. SCRIBNER, S.; COLE, M. The psycology of literacy. Cambrigde: Harvard University Press, 1981.

SNYDER, I. The literacy wars: why teaching children to read and write is a battleground in Australia. Australia: Allen \& Unwin, 2008.

SØBY, M. Digital competence - from education policy to pedagogy: the Norwegian context. In: LANKSHEAR, C.; KNOBEL, M. Digital literacies. New York: Peter Lank, 2008. p.119-150.

STREET, B. V. Literacy in theory and practice. Cambridge: Cambridge University Press, 1984. THOMPSON, J. Ideologia e cultura moderna: teoria social crítica na era dos meios de comunicação de massa. Petrópolis: Vozes, 2000. 


\section{NOTAS}

${ }^{1}$ A esse respeito, ver http://www.dn.pt/inicio/globo/interior.aspx?content_ id=1773616\&seccao=Europa. Acesso em: 21 jun. 2011.

${ }^{2}$ A pouca atenção dos autores à internet é bastante justificável, porquanto a noção de internet que até então se tinha era a de um meio de comunicação one-way, tal como as demais mídias de massa. Antes do começo do século atual, pouco ainda se falava, portanto, em participação ativa, interatividade e agência, características típicas da segunda fase da web.

${ }^{3}$ Bots, redução da palavra inglesa Robots, são um tipo de dispostivo usado para simular ações humanas repetidas vezes de maneira padrão, o que permite criar contas (identidades) falsas (principalmente em redes sociais).

${ }^{4}$ Estou tomando o termo "virtual" no sentido atribuído por Lévy (2001) como "potência", isto é, o virtual se caracterizaria como algo potencialmente real, ou possível de ser realizado. Ao me referir às escolas públicas brasileiras como instituições que, em geral, se encontram na era "pré-virtual", estou querendo dizer que elas, na sua maioria, ainda não vislumbraram meios de realizar, ou, pelo menos, de tornar possível, o uso efetivo da internet nas práticas de letramento escolar.

${ }^{5}$ Embora já existam hoje muitos cursos presenciais e a distância de formação continuada de professores e de gestores, que lidam com questões relativas ao uso das tecnologias digitais na educação, a grande maioria dos profissionais da educação não tem acesso a esses cursos, que, por sua vez, ainda são insuficientes para atender a toda a demanda.

Recebido: $13 / 06 / 2013$

Aprovado: 21/03/2014

Contato:

Universidade Estadual de Campinas

Instituto de Estudos da Linguagem.

Rua Sérgio Buarque de Holanda, 571 Cidade Universitária

Campinas | SP | Brasil

CEP 13.083-859 